\title{
Comunicación y noticias falsas en relación al COVID-19: algunas reflexiones sobre la información, la desinformación y propuestas de mejora
}

Communication and fake news in relation to COVID-19: some reflections on information, disinformation and proposals for improvement

\author{
Francisca Ramón Fernándeza \\ a Escuela Técnica Superior de Ingeniería del Diseño (ETSID), Universitat Politècnica de València, España
}

\section{Resumen}

Las noticias falsas que se han producido durante la crisis sanitaria del COVID-19 han supuesto un reto entorno a la información en el ámbito de la salud. El objetivo del presente trabajo es reflexionar sobre la información y desinformación que se ha producido en relación al COVID-19, las noticias falsas y las consecuencias en los ciudadanos, así como indicar el escenario actual sobre las noticias falsas y las medidas que se adoptan. Se constata que la proliferación de las noticias falsas y los mecanismos para evitar su propagación no disponen de una regulación específica, y el comportamiento de la población deriva del consumo de información no veraz. Se sugiere la aplicación de la inteligencia artificial, mediante algoritmos, además de protocolos de buenas prácticas para evitar la difusión de las noticias falsas en materia de salud, y aprobación de una normativa específica que regule las medidas para luchar contra las fake news.

Palabras clave: Comunicación; noticias falsas; COVID-19; salud; información.

\begin{abstract}
The fake news generated during the health crisis of COVID-19 has provided a challenge for information in the health field. The objective of this work is to reflect on the information and disinformation circulating on COVID-19, on the fake news and the consequences for the citizens, and tho indicate the current scenario of the fake news and the measures that are adopted. It is verified that the proliferation of fake news and the mechanisms to prevent its dissemination do not have specific regulations, and the behavior of the population is driven by the consumption of untruthful information. The application of artificial intelligence is suggested, through algorithms, and good practice protocols to prevent the dissemination of health fake news, and also the adoption of specific regulation on measures to fight against fake news.
\end{abstract}

Key words: Communication; fake news; COVID-19; health; information. 


\section{Introducción}

a Organización Mundial de la Salud modificó la situación de emergencia de salud pública por el COVID-19 a la condición de pandemia internacional el 11 de marzo de 2020, como indicó Redacción Médica (2020). A partir de ese momento, en nuestro país se produjo un cambio en el escenario político, social y jurídico. Se provocaron cambios en el comportamiento de los ciudadanos derivados de la declaración del estado de alarma por el Real Decreto 463/2020, posteriormente prorrogado por los Reales Decretos: 476/2020, 487/2020 y 492/2020, en aplicación de lo indicado en el artículo 116 de la Constitución Española y la Ley Orgánica 4/1981.

Uno de los principales derechos fundamentales es el indicado en el artículo 20, d) de la Constitución Española, el derecho "a comunicar o recibir libremente información veraz por cualquier medio de difusión", consagrado también en el artículo 19 de la Declaración Universal de los Derechos Humanos, aprobada por la Asamblea General de Naciones Unidas (1948) al establecer que:

Todo individuo tiene derecho a la libertad de opinión y de expresión; este derecho incluye el no ser molestado a causa de sus opiniones, el de investigar y recibir informaciones y opiniones, y el de difundirlas, sin limitación de fronteras, por cualquier medio de expresión.

El ejercicio de este derecho no se puede restringir mediante ningún tipo de censura previa (Corredoira y Alfonso, 2007; Corredoira y Alfonso, 2013). Este derecho no queda suspendido por la declaración del estado de alarma, (Sánchez y Corredoira y Alfonso, 2017) ya que según el artículo 58 de la Carta Magna, los derechos reconocidos en el artículo 20, apartados a) y d) sólo podrán ser suspendidos cuando se acuerde la declaración del estado de excepción o de sitio, lo cual no es el caso (Cotino, 2020), a pesar de que algunos medios de comunicación consideran que el estado de alarma actual es un estado de excepción encubierto (Alonso, 2020; Amelang, 2020; Díaz, 2020).

Es la primera vez que nuestro país se enfrenta a una situación sin parangón, ya que la anterior crisis sanitaria del ébola no llegó al estado de alarma (Ibáñez, 2019). Sin embargo, al igual que ocurrió con el ébola, en el caso del COVID-19, la comunicación sanitaria no se ha producido de forma unidireccional, sino multidireccional, ya que la información de los ciudadanos ya no se produce sólo a través de los facultativos, sino también a través de los medios de comunicación, principalmente online como periódicos, blogs, foros o redes sociales (Guzmán, 2018).
Derecho de información y el derecho a la información

El Real Decreto 463/2020 establece en su artículo 19, referente a los medios de comunicación de titularidad pública y privada que "quedan obligados a la inserción de mensajes, anuncios y comunicaciones que las autoridades competentes delegadas, así como las administraciones autonómicas y locales, consideren necesario emitir". Por su parte, la Orden INT/228/2020, por la que se establecen criterios para la aplicación de la anterior norma, en su punto quinto sobre la comunicación y avisos a la población, indica que:

con el fin de garantizar una comunicación pública homogénea y adaptada a la naturaleza de la crisis, y de facilitar a los ciudadanos su derecho a la información (...) la inserción de mensajes, anuncios y comunicación se comunicarán previamente al CENEM (Ministerio del Interior, 2020, p. 2).

Además, la Dirección General de Protección Civil y Emergencias especifica que:

se establecerán los mensajes que, en coordinación con las Autoridades Sanitarias, se estime conveniente difundir a través de la función de comunicación pública del ámbito de la protección civil, bien de oficio, bien a iniciativa y propuesta de los órganos correspondientes de las Comunidades y Ciudades con Estatuto de Autonomía (p. 25416).

Todo ello en aplicación de lo preceptuado en la Ley 17/2015, en su artículo 7 bis, 8, que establece que:

Los medios de comunicación están obligados a colaborar de manera gratuita con las autoridades en la difusión de las informaciones preventivas y operativas ante los riesgos y emergencias en la forma que aquéllas les indiquen y en los términos que se establezcan en los correspondientes planes de protección civil (p. 57418).

El Derecho a la información positivizado en los textos legislativos regula una actividad social que es la información y la actividad de informar, es decir, el Derecho de la información (Desantes; 1976; Ibáñez, 2019). No hay que olvidar también la invocación del artículo 18 de la Constitución, por cuando se establece por ley una limitación del uso de la informática para garantizar el honor y la intimidad personal y familiar de los sujetos, así como el pleno ejercicio de los derechos que le corresponden, y la Ley Orgánica 1/1982. 
Una pandemia contra otra pandemia: las noticias falsas versus COVID-19

Desde luego, la percepción de la información por parte de un sujeto influye en su posterior comportamiento en el ámbito social. El discernimiento entre lo que es verdad o es mentira en muchas ocasiones no es fácil de dilucidar, la obtención de la información y su verificación se convierten en esencial (Barroso, 2019), y hay que apostar por la "información higiénica", la que no está contaminada.

Nos encontramos en el ámbito de la salud con bulos, postverdades, verdades a medias, mentiras parciales o falsas noticias (Gómez, 2018; Rodríguez, 2019). En el caso del coronavirus hacen que el ciudadano tome decisiones que pueden afectar a su propia salud (Lizaraso y Del Carmen, 2020). Además, no podemos olvidar que nos encontramos con el perfil de consumidor, con el de prosumidor, ciudadano y paciente, en su caso. Pero no siempre se activan todos estos roles, ya que se puede adoptar una actitud pasiva 0 activa a la hora de participar en el ámbito de la comunicación (Revuelta, 2019).

El derecho a la protección de la salud, que se establece en el artículo 43 de la Constitución y que establece la competencia de los poderes públicos para organizar y tutelar la salud de los ciudadanos a través de medidas preventivas, en el caso de los medios de comunicación en muchas ocasiones no se cumple.

Recibimos cada día, a través de distintos canales - medios (mensajería de móvil, periódicos, redes sociales, televisión...), información que puede ser falsa, no contrastada y que incita a la confusión. Junto a ello, actualmente el tema del COVID-19 se ha convertido en el tema estrella de consultas por internet (Contreras, 2020), y la generación de contenidos no está sujeta a ningún control sobre su veracidad o falsedad.

El consumidor no tiene la suficiente preparación para reconocer si una fuente de información es fiable, o si la información que recibe es falsa (Revuelta, 2019). El ritmo de la información generada adquiere tal rapidez que no nos da tiempo a comprobar su procedencia, no disponemos de tiempo ni de la paciencia suficiente para averiguar y contrastar (Revuelta, 2019). Otro de los factores es la presentación del mensaje, si es un texto largo tendemos a rechazarlo, porque nos cuesta más trabajo leerlo. Consumimos más fácilmente información directa, o a través de las imágenes, por lo que la inmediatez es la clave para que una fake new se difunda de forma más rápida.

Se entiende por fake news "las noticias fabricadas que se difunden casi siempre con intención de manipular a la opinión pública y que se difunden rápidamente porque los usuarios no verifican la fuente y comparten la noticia por su atractivo o su impacto" (Muñoz-Machado, 2020, p. 123). Se asemeja a lo que se ha denominado posverdad Domínguez (2020), y que la Real Academia Española la define como "distorsión deliberada de una realidad, que manipula creencias y emociones con el fin de influir en la opinión pública y en actitudes sociales".

Las fake news se convierten en un fenómeno en el que la mentira impera y se produce la desinformación (Caldevilla, 2020; Montuori, Ademir y Borges, 2020). Sin embargo, va mucho más allá, porque la información falsa, la mentira, se convierte en una herramienta de control de masas en aras de establecer su comportamiento para lograr un objetivo: la manipulación. Su creación sigue las denominadas cuatro "P": pasión, política, propaganda y pago (Muñoz-Machado, 2020). Además, cuando se descubre el bulo, se produce una desconfianza del sujeto hacia los medios de comunicación que los han emitido. ¿Qué es verdad y qué es mentira? Se plantea el ciudadano de a pie.

Según datos facilitados por la consultora Gartner (Flores, 2020), las noticias falsas tienen una velocidad de difusión elevada, y son replicadas por los sujetos con una probabilidad superior al $70 \%$ que una noticia verdadera. Está demostrado que el sujeto cree antes una noticia falsa que una verdadera, por la capacidad de convicción que la hace creíble (Blanco, 2020). Esta rapidez de difusión de la falsedad también es debido a los perfiles falsos que se encuentran en las redes sociales. Cuando buscamos, etiquetamos o compartimos información, los llamados social bots (Muñoz-Machado, 2020) replican la información de forma exponencial. Son cuentas falsas, automatizadas, de personas simuladas, creados específicamente para difundir información falsa.

En el caso del COVID-19 nos hemos encontrado con esta situación en la que se ha afirmado lo siguiente, sin ánimo exhaustivo (Domínguez y Amador, 2020; Maldita. es. Maldito bulo, 2020; Onda Cero, 2020):

a) Es un virus creado en un laboratorio con la intención de control político.

b) Es un virus que se cura bebiendo lejía.

c) Es todo un invento, no hay virus.

d) Es como una gripe, no es peligroso.

e) El virus sobrevive en el asfalto, hay que quitarse los zapatos al llegar a casa.

f) La nicotina protege contra el virus.

g) Se contagia el virus por el maquillaje.

h) La cocaína te protege contra el virus.

i) Beber mucha agua o hacer gárgaras con agua tibia y sal o vinagre previene la infección por el virus. 
Por lo tanto, hay que diferenciar las fuentes de información, las oficiales que proceden del ejecutivo, partidos políticos, sindicatos, asociaciones, empresas, expertos, e instituciones que gestionan la emergencia; y las no oficiales como son las víctimas y afectados (MayoCubero, 2020).

Como señala acertadamente Muñoz-Machado (2020):

Los estudios también demuestran que las personas prefieren las informaciones que confirman sus convicciones, consideran las informaciones consistentes con sus ideas más creíbles que aquellas que no lo hacen, y se inclinan a aceptar más la información que les complace que la que no. En el mismo sentido, el convencimiento de una persona sobre una determinada cuestión puede evitar que contraste los datos publicados en la noticia. También se ha demostrado que la gente tiende a recordar más la información que le hace sentir bien, que el contexto de esa información, y que normalmente se acepta como cierta la información que se conoce frente a la que no (p. 125).

En el caso de la actual pandemia tenemos una fuente de información fiable, el Boletín Oficial del Estado, en el que se publican las normas que el Gobierno va aprobando con la finalidad de regular la situación. Ello es indiscutible, pero sí que se discute la interpretación que se realiza de la norma positiva, y que puede dar lugar también a fake news, con la finalidad de alarmar a la población sobre las posibles consecuencias (el caso, por ejemplo, de la expropiación de la propiedad privada), o incluso en la alteración del texto publicado en diversos medios de comunicación, con la intención de provocar la confusión del público.

Un ejemplo claro de esta manipulación relacionada con la interpretación de las normas ha sido la aparición en los medios de comunicación de imágenes relacionadas con la permisión de salida de los niños, en el que se insertaban imágenes antiguas dando a entender que no se cumplían las condiciones que marcaba la legislación.

Hay que tener en cuenta que en el caso del COVID-19 se desarrolla en el ámbito de la salud, y que las cifras que se van proporcionando sobre el número de contagios, fallecimientos e ingresos difieren de un medio de comunicación a otro, estableciéndose un "baile de cifras" que provoca la ansiedad y la desinformación de la población.

No hay que olvidar que en el caso de crisis sanitarias, como la que estamos viviendo, y precisamente en esa situación es donde se muestra la responsabilidad social de los medios en la información que facilitan sobre la misma (Mayo-Cubero, 2020). El destinatario de esa información tiene que confiar en la fuente de esa información, ya que dependerá de su credibilidad y honestidad el comportamiento que vaya a adoptar, por ejemplo, en la prevención del contagio de la pandemia.

Conceptos como transparencia y nuevas tecnologías de la información y comunicación (TICs) entran en juego para crear un clima de confianza en el receptor de la información. Pero ello no se mantiene inmutable en el caso de las denominadas fuentes oficiales, ya que según datos cualquier información oficial puede ser adulterada, a través de la manipulación con imágenes o textos.

La falta de confianza del ciudadano en las fuentes oficiales viene también determinada por la falta de credibilidad e incumplimiento de normas éticas y deontológicas (Mayo-Cubero, 2020). La ocultación de datos o la manipulación de la información son ejemplos claros de una mala gestión en el ámbito del derecho a la información de los sujetos reconocida en el texto constitucional (Mayo-Cubero, 2017).

Propuestas de mejora: inteligencia artificial, listados de fuentes, protocolos de buenas prácticas

Nos encontramos ante una pandemia con la que hay que luchar digitalmente (Forteza y Costa, 2019; Ramonet, 2020). No es menos cierto que en la lucha contra las fake news se tiene también que aplicar las herramientas digitales, la inteligencia artificial principalmente. El origen de las noticias falsas se encuentra en las tecnologías disruptivas (Flores, 2020). Aunque inicialmente la propagación se produce por los sujetos, la inteligencia artificial, a través de algoritmos y de bots, puede frenar la expansión, y además servir a los destinatarios de la información para comprobar si la información que están recibiendo es cierta o falsa, con independencia de una fuente oficial o que se considere fiable. Se desarrollaría a través de bots y algoritmos de verificación de la información (Flores, 2020), para descartar información tóxica, y servir de cribado ante la proliferación de información a la que se expone el sujeto.

Es deber de todo profesional de la información contrastar las fuentes de donde obtiene la misma, y ello es una medida para evitar la propagación de noticias falsas (Moreno, 2020).

Las noticias falsas en ocasiones actúan de placebo, de esperanza para los sujetos que se aferran a ellas considerando que son verdad, porque les interesa lo que la noticia indica. De ahí, la importancia de que los propios sujetos destinatarios de las noticias calibren si procede de una fuente fiable o no, hay que actuar de cortafuegos (Moreno, 2020).

La participación ciudadana, la transparencia, la 
responsabilidad y el espíritu crítico son otras de las herramientas válidas en la lucha contra las fake news.

La elaboración de listados de fuentes fiables como ha realizado la Asociación Española de Comunicación Científica (2020), diferenciando entre fuentes de referencia, fuentes para profesionales de la comunicación y fuentes dirigidas al público en general, es otra de las formas idóneas para luchar contra la información falsa 0 adulterada. Este listado debía ser facilitado por todos los medios de comunicación y ser accesible de forma fácil a los ciudadanos, así como realizar su difusión a todos los colectivos implicados, para evitar la consulta de fuentes erróneas y así controlar la expansión de la información falsa.

La Escuela Andaluza de Salud pública (2020) publicó una serie de pautas para una información responsable, siguiendo las indicaciones de First Draft news (2020). Se mencionaban las siguientes (López, Luque y Martín, 2020):

a) Evitar un lenguaje sensacionalista;

b) Seleccionar las imágenes que ilustran la información;

c) Evitar especular sobre posibles escenarios;

d) Proporcionar al lector acciones específicas que pueda llevar a cabo;

e) Indicar las fuentes oficiales de información;

f) Consultar con expertos en relación a las investigaciones que se consulten;

g) Reflexionar sobre si dar cobertura a los rumores;

h) Contenido accesible y comprensible;

i) Evitar un lenguaje despectivo; y

j) Llenar los vacíos de información proporcionando un periodismo de servicio.

También puede ser útil como medida en la lucha contra las fake news el establecimiento de una regulación 0 autorregulación (Corredoira y Alfonso, 1996; Corredoira y Alfonso 2001), así como la actuación de los sujetos afectados contra los sitios donde se publique información falsa (Muñoz-Machado, 2020).

La Comisión Europea (2019), a finales del año 2018, elaboró una Comunicación conjunta al Parlamento Europeo, el Consejo Europeo, el Consejo, el Comité Económico por la que se emitió un informe sobre la ejecución del Plan de acción contra la desinformación. La Comisión Europea indicó la adopción del Código de conducta autorregulador en materia de desinformación por parte de las principales plataformas (Facebook, Google, Twitter). En dicho informe se indicaba que las Instituciones Europeas trabajaron en colaboración en distintos ámbitos como: Aumentar la sensibilización sobre la desinformación; mejorar la comunicación sobre las políticas de la Unión Europea; potenciar la capacidad de la Unión Europea para reaccionar ante la desinformación; reforzar la resiliencia de la sociedad a través de la alfabetización mediática y capacitar a la sociedad civil.

En este mismo informe se indicó que se puso en marcha por parte de la Comisión Europea el Observatorio Social de Desinformación y Análisis de Medios de Comunicación Sociales (SOMA), para facilitar la creación de redes, así como el intercambio de conocimientos y desarrollar mejores prácticas entre verificadores de datos independientes.

En el informe de la Comisión Europea al Parlamento Europeo, al Consejo Europeo, al Consejo, al Comité Económico y Social Europeo y al Comité de las Regiones sobre la aplicación de la Comunicación "La lucha contra la desinformación en línea: Un enfoque europeo" publicado en 2018, establece el apoyo al periodismo de calidad "como un elemento esencial de una sociedad democrática. Los medios de comunicación y el periodismo de calidad pueden descubrir y diluir la desinformación, transmitiendo a los ciudadanos información de calidad y diversa" (Comisión Europea, 2018, p. 12).

La Resolución del Parlamento Europeo, de 15 de junio de 2017, sobre las plataformas en línea y el mercado único digital (2016/2276(INI)) destacó:

la importancia de actuar contra la divulgación de noticias
falsas; pide a las plataformas en línea que faciliten a los
usuarios herramientas para denunciar las noticias falsas, de
manera que se pueda informar a otros usuarios de que se ha
puesto en entredicho la veracidad de los contenidos; señala
al mismo tiempo que el libre intercambio de opiniones es un
elemento fundamental de la democracia y que el derecho
a la privacidad también se aplica a los medios sociales;
destaca el valor de la libertad de prensa en relación con la
facilitación de información fiable a los ciudadanos.

Y pidió el Parlamento a la Comisión "que analice en profundidad la situación actual y el marco jurídico en lo relativo a las noticias falsas y que examine si es posible utilizar la vía legislativa para limitar la difusión y propagación de contenidos falsos".

También mencionar la existencia de un portal elaborado por la Unión Europea, denominado 1de2.edu, donde, a través de una app, se puede comprobar el nivel de capacidad para detectar información falsa. Es a través de la gamificación, donde el ciudadano puede comprobar si es más susceptible a reconocer la veracidad de la información o no.

La Unión Europea como medida para evitar la difusión y propagación ha abierto una web sobre la información falsa (Laguna, 2020), denominada Fighting disinformation 
(European Commision, 2020). En esta web se indica la existencia de desinformación en el ámbito de la salud, y en el caso del COVID-19 recomienda la consulta de sitios oficiales como la Organización Mundial de la Salud, y el Centro europeo para la prevención y el control de enfermedades.

Recomienda no compartir información que no esté verificada y sea procedente de fuentes dudosa, para evitar la propagación de las noticias falsas. La web también establece un enlace a otra web referente al análisis de la información falsa: EUvsDisinfo (2019).

Se indica en la web una recopilación de hechos con la finalidad de que el ciudadano que tiene dudas sobre alguna de las informaciones que ha leído, pueda conocer los hechos, y que pasamos a indicar:

1. Las medidas de contención en toda Europa son temporales y no señalan el fin de la democracia o los valores liberales europeos;

2. El número creciente de víctimas en Europa prueba que el COVID-19 es una enfermedad nueva y peligrosa causada por el coronavirus, no simplemente una cepa recurrente de la gripe estacional;

3. Actualmente no existe una cura conocida para el coronavirus;

4. Si bien la Unión Europea tiene como objetivo trabajar de forma cooperativa y constructiva con sus vecinos, siempre revelaremos desinformación perjudicial y sus fuentes;

5. No existe un vínculo entre el coronavirus y la tecnología 5G;

6. Todos corremos el riesgo de ser infectados por el coronavirus;

7. Nadie está utilizando la crisis del coronavirus como excusa para imponer vacunas masivas;

8. La Unión Europea siempre ha apoyado las inversiones de los Estados miembros en salud pública;

9. Los países de la Unión Europea siguen siendo los mejores socios entre sí y están intensificando su solidaridad;

10. Las instituciones y los países de la Unión Europea han hecho más por los europeos que cualquier otro país, incluido trabajar 24/7 para aumentar los suministros médicos;

11. La Unión Europea se ocupa de los asuntos de los que es responsable: obtener suministros críticos a través de las fronteras, mantener a los gobiernos coordinando y compartiendo información, y obtener recursos financieros y experiencia donde se necesiten para que los gobiernos puedan concentrarse en lo más importante: la salud pública;

12. La Unión Europea está reuniendo dinero para que las empresas produzcan lo que necesitamos para responder a la crisis: máscaras, guantes, trajes protectores y otros equipos médicos;
13. Schengen ha sido una parte central de nuestra respuesta al coronavirus. Mantiene las fronteras abiertas para suministros y servicios durante todo el día;

14. Alos virus no les importa de dónde eres. No les importa de qué color eres o qué pasaporte tienes. En diferentes partes del mundo, las personas están tratando de culpar a la enfermedad de diferentes grupos, llamándolo el virus europeo, el virus chino, el virus estadounidense; $y$

15. La Unión Europea tiene algunas de las normas de protección de datos y privacidad más sólidas del mundo. El coronavirus no cambia eso.

La Unión Europea también recomienda que se promueva la información a través de fuentes autorizadas, que se denote el contenido que se verifica como falso 0 engañoso y que elimine el contenido ilegal o dañoso.

Más recientemente, la Comisión Europea en la Comunicación conjunta al Parlamento Europeo, al Consejo Europeo, al Consejo, al Comité Económico y Social Europeo y al Comité de las Regiones sobre Abordar la desinformación de COVID-19: contrastando los datos, de 06 de junio 2020, se ha pronunciado sobre la desinformación, y tomando como punto de partida el Plan de acción contra la desinformación mencionado anteriormente, lo ha hecho en los siguientes términos:

La pandemia de COVID-19 (coronavirus) ha ido acompañada de una «infodemia» sin precedentes. Según la Organización Mundial de la Salud (OMS), ese torrente de información sobre el virus - a menudo falsa o inexacta y rápidamente propagada a través de las redes socialespuede generar confusión y desconfianza y minar la eficacia de la respuesta de la sanidad pública. Esta «infodemia» se alimenta de los temores más primarios. El confinamiento social ha obligado a millones de personas a permanecer en sus hogares y aumentado el uso de las redes sociales como medio de acceso a la información precisamente en un momento en el que las plataformas en línea, los verificadores de datos y los usuarios de las redes sociales están notificando millones de publicaciones falsas 0 engañosas. Habida cuenta de la novedad del virus, las lagunas en los conocimientos al respecto han creado un caldo de cultivo idóneo para la difusión de relatos falsos o engañosos. Esta situación requiere, tomando como punto de partida el Plan de acción contra la desinformación, una actuación más coordinada y acorde a nuestros valores democráticos que haga frente a los riesgos para las sociedades abiertas. Nuestras instituciones democráticas y nuestros valores comunes, entre los que se hallan la libertad de expresión y la libertad y pluralidad de los medios de comunicación, son el fundamento de la resiliencia de nuestras sociedades frente a los desafíos de la pandemia de COVID-19 (Comisión Europea, 2020, p. 1). 
La Comisión Europea realiza una serie de recomendaciones y actuaciones a través de la mejora de la cooperación dentro de la Unión Europea; cooperación con terceros países y organizaciones internacionales; aumento de la transparencia de las plataformas en línea; entre otras.

Como señala Badillo (2019, p. 23), las iniciativas de verificación en línea, los verificadores o fact-checkers, constituyen unas "herramientas para que los periodistas comprueben la veracidad de un dato o la credibilidad de una fuente online, buscadores para identificar el origen de una imagen o comprobar si se ha publicado antes ( $\mathrm{y}$ corresponde a otro momento y lugar) o agregadores de noticias falsas que permiten comprobar su veracidad".

La elaboración de una normativa contundente es una de las claves para frenar las fake news. En España, si bien se apuesta por un cambio en la legislación actual. No obstante, se rechazó la Proposición no de Ley relativa al impulso de las medidas necesarias para garantizar la veracidad de las informaciones que circulan por servicios conectados a Internet y evitar injerencias que pongan en peligro la estabilidad institucional en España, que fue presentada al Congreso de los Diputados el 19 de diciembre de 2017, y calificada el 9 de enero de 2018.

Posteriormente, se publicó el informe "Desinformación en el ciberespacio" por parte del Centro Criptológico Nacional (CCN-CERT, 2019), que establece un decálogo de seguridad frente a las campañas de desinformación: analizar la fuente; dudar de los pantallazos o screenshots que se reciban por redes sociales; quién comparte y el contexto; atención a las cuentas falsas "humanas"; no ser parte del algoritmo; leer la letra pequeña; alerta con los contenidos patrocinados de origen desconocido; desconfiar de las estrellas invitadas; pensamiento crítico y cabeza fría; y reflexionar antes de propagar la información.

En marzo de 2019 se aprobó por la Comisión mixta de Seguridad Nacional del Congreso de los Diputados, con modificaciones, el informe de la ponencia para el estudio de diversas cuestiones relativas a la ciberseguridad en España, y en el que se indicó que:

es necesario llegar a una definición consensuada en esta materia, que todos los actores de la cadena informativa utilicen como base común para fomentar así la no difusión de estas noticias. Para ello es necesaria la implantación de técnicas de verificación de contenidos que cumplan estándares internacionales. En esta materia continúa afirmando que es muy peligroso que una autoridad administrativa se atribuya la facultad de etiquetar lo que es falso y lo que no (Cortes Generales, 2019, p. 16).
Y que:

las noticias falsas son un peligro para las sociedades democráticas, pero que la regulación de esa materia es muy complicada ya que las prohibiciones generales basadas en ideas vagas y ambiguas son incompatibles con las normas internacionales sobre libertad de expresión (Cortes Generales, 2019, p. 16).

La Orden PCI/487/2019, de 26 de abril, por la que se publica la Estrategia Nacional de Ciberseguridad 2019, aprobada por el Consejo de Seguridad Nacional hace referencia a que:

las campañas de desinformación, hacen uso de elementos como las noticias falsas para influir en la opinión pública. Internet y las redes sociales amplifican el efecto y alcance de la información transmitida, con potencial aplicación en contra de objetivos como por ejemplo organizaciones internacionales, Estados, iniciativas políticas o personajes públicos 0 incluso a procesos electorales democráticos (Ministerio de la Presidencia, Relaciones con las Cortes e lgualdad, 2019, p. 43444).

Y dentro del Capítulo 4 de la citada Orden PCI/487/2019, referente a las líneas de acción y medidas, en la línea de acción 7 , que se refiere al desarrollo de una cultura de ciberseguridad, establece como medida 5 "Promover un espíritu crítico en favor de una información veraz y de calidad y que contribuya a la identificación de las noticias falsas y la desinformación" (Ministerio de la Presidencia, Relaciones con las Cortes e lgualdad, 2019, p. 43453).

\section{Conclusiones}

Las fake news son un instrumento de control social, que buscan la desinformación, el descrédito y la confusión con el objetivo de ejercer un mecanismo de decisión y comportamiento de los sujetos. En el caso del COVID-19 se han convertido en otra pandemia, una pandemia informativa, que busca intoxicar al público de un virus, el de la desinformación, el de la falta de información veraz.

La necesidad de establecer herramientas 0 instrumentos para evitar las fake news no radica sólo en una labor subjetiva del ciudadano, sino que la inteligencia artificial nos puede facilitar, mediante la utilización de algoritmos, el descarte de una información adulterada, y evitar su propagación y expansión. También el diseño de bots que permitan contrastar la información con fuentes fiables e identificar la falsa.

El poder de las fake news en el ámbito de la salud puede ser devastador, ya que nos encontramos ante una información muy sensible y con unas consecuencias para el ámbito sanitario y social que pueden derivar en 
pérdidas económicas sustanciales. Otro de los aspectos a considerar en la sociedad de la información es la protección de datos personales, datos que en materia de salud son especialmente sensibles y están sujeto a limitaciones legales como categoría especial de datos según indica la Ley Orgánica 3/2018, en su artículo 9, teniendo en cuenta lo ya indicado en el artículo 9 del Reglamento (UE) 2016/679 y especialmente el artículo 85 , que se refiere al tratamiento y libertad de expresión y de información.

La postulación de la Unión Europea a través de una web en la que se establecen recomendaciones en torno a la desinformación que se está produciendo en relación al COVID-19 es una buena práctica que favorece la concienciación de evitar fuentes no fiables ni contrastadas.

Sin embargo, consideramos que una de las medidas más positivas para luchar contra las fake news es elaborar una legislación, o un cambio en la existente, que contemple una prohibición de utilizar información falsa, así como las medidas a adoptar en el caso de la infracción de la misma (Corredoira y Alfonso, 2015; Blázquez, 2019; Coarasa, 2020; Chaves, 2020).

\section{Agradecimientos}

Trabajo realizado en el marco del Proyecto $I+D+i$ «Retos investigación» del Programa estatal de I+D+i orientado a los Retos de la Sociedad del Ministerio de Ciencia, Innovación y Universidades: RTI2018-097354-B-100 (2019-2022). Investigadores Principales: Dr. Javier Plaza Penadés, Catedrático de Derecho Civil, y Dra. Luz M. Martínez Velencoso, Catedrática de Derecho Civil. Universitat de València-Estudi General, y Proyecto de I+D+i Retos MICINN "Derechos y garantías frente a las decisiones automatizadas en entornos de inteligencia artificial, loT, big data y robótica" (PID2019-108710RB-I00, 2020-2022). Investigador principal: Dr. D. Lorenzo Cotino Hueso. Catedrático de Derecho Constitucional. Universitat de València, y del Microcluster VCL/ CAMPUS "Derecho Sanitario, Genética y Protección Social", Universitat València-Universitat Politècnica de València.

\section{Referencias bibliográficas}

Alonso,A. (2020, 11 de abril). España frente al coronovirus: ¿Estado de alarma o estado de excepción?. La Vanguardia. Recuperado de https://www. lavanguardia.com/politica/20200401/48249828592/ espana-frente-al-coronavirus-estado-de-alarma-oestado-de-excepcion.html

Amelang López, D. (2020, 29 de marzo). ¿Estado de alarma o estado de excepción encubierto?. Blogs Público. Recuperado de https://blogs.publico.es/ red-juridica/2020/03/29/estado-alarma-excepcion/

Asociación Española de Comunicación Científica (2020, 8 de abril). Lista de fuentes fiables sobre el nuevo coronavirus. AECC. Noticias de comunicación científica. Recuperado de https:// www.aecomunicacioncientifica.org/lista-de-fuentesfiables-sobre-el-nuevo-coronavirus/

Badillo, A. (2019, 14 de mayo). La sociedad de la desinformación: propaganda, "fake news" y la nueva geopolítica de la información. Documento de trabajo 8. Real Instituto Elcano. Recuperado de http://www. realinstitutoelcano.org/wps/wcm/connect/fc1e5338b663-4254-943e-15b1d154e62e/DT8-2019Badillo-sociedad-de-desinformacion-propagandafake-news-y-nueva-geopolitica-de-informacion. pdf?MOD=AJPERES\&CACHEID=fc1e5338-b6634254-943e-15b1d154e62e

Barroso, F. J. (2019). Los procesos de gestión y obtención de la información desde los medios de comunicación social. Su utilidad práctica aplicada. En La función de inteligencia en la gestión de emergencias $y$ catástrofes (pp. 167-188). Madrid: Ministerio de Defensa, Instituto Español de Estudios Estratégicos. Recuperado de https://dialnet.unirioja.es/servlet/ libro?codigo $=732785$

Blanco Alfonso, I. (2020). Posverdad, percepción de la realidad y opinión pública: Una aproximación desde la fenomenología. Revista de Estudios Políticos, 187, 167-186.

Blázquez Ochando, M. (2019). El problema de las noticias falsas: detección y contramedidas. En $M^{a}$. T. Fernández Bajón, y G. A. Torres Vargas (coord.), Verdad y falsedad de la información (pp. 13-43). Universidad Autónoma de México: México.

Caldevilla Domínguez, D. (2020). Profesionales y posverdad: La responsabilidad colectiva como arma contra la falacia digitalizada. aDResearch: Revista Internacional de Investigación en Comunicación, 21, 70-83. https://doi.org/10.7263/ adresic-021-04

Centro Criptológico Nacional. Ministerio de Defensa (2019). Desinformación en el ciberespacio. Centro Criptológico Nacional: Madrid. Recuperado de https://www.ccn-cert.cni.es/informes/informesde-buenas-practicas-bp/3549-ccn-cert-bp-13desinformacion-en-el-ciberespacio/file.html 
Coarasa, R. (2020, 6 de abril ). Justicia revisará la ley para que los autores de bulos "no se vayan de rositas". La Razón. Recuperado de https://www.larazon.es/ espana/20200406/k4pxfhx6fzgjvh7b2iws2k26wy. html

Comisión Europea. (2018). La lucha contra la desinformación en línea: Un enfoque europeo. Informe de la Comisión al Parlamento Europeo. Recuperado de https://ec.europa.eu/transparency/ regdoc/rep/1/2018/ES/COM-2018-794-F1-ES-MAINPART-1.PDF

Comisión Europea. (2019, 5 de noviembre). Unión Europea vs. Desinformación. Recuperado de https://ec.europa.eu/spain/news/20191105_eu-vsdisinformation_es

Comisión Europea (2019). Informe sobre la ejecución del Plan de acción contra la desinformación. Recuperado de https://eur-lex.europa.eu/legalcontent/ES/TXT/PDF/?uri=CELEX:52019JC0012\&fr om=EN

Comisión Europea (2020). Comunicación conjunta al Parlamento Europeo, al Consejo Europeo, al Consejo, al Comité Económico y Social Europeo $y$ al Comité de las Regiones sobre Abordar la desinformación de COVID-19: contrastando los datos. Recuperado de https://eur-lex.europa.eu/ legal-content/ES/TXT/PDF/?uri=CELEX:52020JC00 08\&from $=E N$

Constitución Española. (1978). Boletín Oficial del Estado, 311, 1-111.

Contreras. (2020, 29 de marzo). El demoledor impacto del COVID-19 en los medios de comunicación en España. El diario.es. Recuperado de https://www. eldiario.es/zonacritica/demoledor-impacto-COVIDcomunicacion-Espana_6_1011108894.html

Corredoira y Alfonso, L. (1996). Unión Europea e información: análisis de un nuevo régimen jurídico para España. Comunicación y sociedad 9(12), 129-173. Recuperado de https://revistas.unav. edu/index.php/communication-and-society/article/ view/35633

Corredoira y Alfonso, L. (2001). Más iniciativas de autorregulación de interneten España. En La libertad de información: gobierno y arquitectura de internet (pp. 187-190). Madrid, España: Universidad Complutense de Madrid.
Corredoira y Alfonso, L. (2007). Lectura de la Declaración Universal de Derechos Humanos de 1948 en el paradigma de la nueva sociedad de la información. Estudio específico del artículo 19. En L. Cotino Hueso (coord.), Libertad en internet: la red y las libertades de expresión e información (pp. 5774). Valencia, España: Tirant lo Blanch.

Corredoira y Alfonso, L. (2013). Agenda de reformas internacionales en materia de control o censura de contenidos. En L. Corredoira y Alfonso, y L. Cotino Hueso (dir.), Libertad de expresión e información en internet: amenazas y protección de los derechos personales. Madrid, España: Centro de Estudios Políticos y Constitucionales.

Corredoira y Alfonso, L. (2015). Los medios en internet: entre la anarquía y la hiperregulación. En L. Núñez Ladeveze, y L. Abad Alcalá (coord.), Periodismo en la red: entre la anarquía y la hiperregulación (pp. 415-440). Madrid, España: Universitas.

Cortes Generales. (2019). Ponencia para el estudio de diversas cuestiones relativas a la ciberseguridad en España. Boletín Oficial de las Cortes Generales, 277, 1-38.

Cotino Hueso, L. (2020). Los derechos fundamentales en tiempos del coronavirus: Régimen general y garantías y especial atención a las restricciones de excepcionalidad ordinaria. El Cronista del Estado Social y Democrático de Derecho, 86-87, 88-101. Recuperado de http://www.elcronista.es/El-Cronistan\%C3\%BAmero-86-87-Coronavirus.pdf.

Chaves, A. (2020, 7 de abril). El Gobierno cambiará la ley para perseguir las fake news. Extradigital. Recuperado de http://www.extradigital.es/elgobierno-cambiara-la-ley-para-perseguir-las-fakenews/

Declaración Universal de Derechos Humanos de 1948. Resolución 217 A. (111). Asamblea General de Naciones Unidas. Recuperado de https:// www.ohchr.org/EN/UDHR/Documents/UDHR_ Translations/spn.pdf

Desantes, J. M. (1976). La función de informar. Navarra, España: Universidad de Navarra.

Díaz Nobile, C. (8 de abril de 2020). ¿Utiliza Sánchez el estado de alarma como un estado de excepción encubierto?. Okdiario. Recuperado de https:// okdiario.com/video/utiliza-sanchez-estado-alarma- 
como-estado-excepcion-encubierto-5426880

Domínguez, L., y Amador Bedolla, C. (2020). El origen del COVID-19: lo que se sabe, lo que se supone y (muy poquito) sobre las teorías de complot. Educación química, 31(2), 3-11. Doi:10.22201/ fq. 18708404e.2020.2.75461

Domínguez Tuset, J. A. (2020, 27 de abril). Fake news: acciones penales y civiles sobre la divulgación y difusión de noticias falsas. Economist \& Jurist. Recuperado de https://www.economistjurist.es/ actualidad-juridica/fake-nwes-acciones-penales-yciviles-sobre-la-divulgacion-y-difusion-de-noticiasfalsas/

European Commision (2020). Fighting disinformation. Recuperado de https://ec.europa.eu/info/live-worktravel-eu/health/coronavirus-response/fightingdisinformation_en

EUvsDisinfo (2020). EUvsDisinfo. Recuperado de https://euvsdisinfo.eu/

Flores Vivar, J. M. (2020). Datos masivos, algoritmización y nuevos medios frente a la desinformación y fake news: bots para minimizar el impacto en las organizaciones. Comunicación y Hombre: Revista Interdisciplinar de Ciencias de la Comunicación y Humanidades, 16, 101-114. Recuperado de https://comunicacionyhombre.com/wp-content/ uploads/2020/02/ESTUDIO-4-corregido.pdf

First Draft news. (2020). Recopilación de noticias y recursos de verificación esenciales para periodistas. Recuperado de https://firstdraftnews. org/

Forteza Martínez, A. y Costa Román, Ó. (2019). La verdad sobre las fake news: una mirada crítica y científica hacia las noticias falsas. En J. Sierra Sánchez, y J. $M^{\mathrm{a}}$ Lavín de la Cavada (coord.), Redes sociales, tecnologías digitales y narrativas interactivas en la sociedad de la información (pp. 81-88). McGraw-Hill Interamericana de España: Madrid.

Gómez de Agreda, A. (2018). Posverdad y "fake new". Falsas noticias, no noticias falsas. Telos: Cuadernos de Comunicación e Innovación, 109, 18-21. Recuperado de https://telos.fundaciontelefonica. com/telos-109-asuntos-de-comunicacion-falsasnoticias-no-noticias-falsas/

Ibáñez Peiró, A. (2019). La Administración y la cobertura informativa en situaciones extraordinarias relacionadas con la salud. La crisis del virus del Ébola. Revista Española de Comunicación en Salud, suplemento 1, 67-79. https://doi.org/10.20318/ recs.2019.4425

Guzmán do Nascimento, B. (2018). Comunicación y salud: La gestión de la crisis del Ébola a través de las redes sociales. Revista Española de Comunicación en Salud, 9(2), 196-202. https://doi.org/10.20318/ recs.2018.4497

Laguna, R. (2020, 3 de abril). La UE abre una página web contra las "fake news" del coronavirus provenientes de Rusia, China y la derecha de EEUU. Valencia Plaza. Recuperado de https:// valenciaplaza.com/la-ue-abre-una-pagina-webcontra-las-fake-news-del-coronavirus-provenientesde-rusia-china-y-la-derecha-de-eeuu

Ley 17/2015. Boletín Oficial del Estado, 164, 5740957435.

Ley Orgánica 4/1981. Boletín Oficial del Estado. 134,12541- 12543.

Ley Orgánica 1/1982. Boletín Oficial del Estado, 115, 12546- 12548.

Ley Orgánica 3/2018. Boletín Oficial del Estado, 294, 119788-119857.

Lizaraso Caparó, F. y Del Carmen Sara, J. (2020). Coronavirus y las amenazas a la salud mundial. Horizonte Médico, 20(1), 4-5. Recuperado de http://www.horizontemedico.usmp.edu.pe/index.php/ horizontemed/article/view/1193/696

López Doblas, M., Luque Martín, N. y Martín Barato, A. (2020, 9 de abril). Medios de comunicación y COVID-19: Pautas para una información responsable. Escuela Andaluza de Salud Pública. Recuperado de https://www.easp.es/web/ coronavirusysaludpublica/medios-de-comunicaciony-covid-19-pautas-para-una-informacionresponsable/

Maldita.es. (2020). El coronovirus y sus bulos: 462 mentiras, alertas falsas $y$ desinformaciones sobre COVID-19. Recuperado de https://maldita. es/malditobulo/2020/04/23/coronavirus-bulospandemia-prevenir-virus/

Mayo-Cubero, M. (2020). News sections, journalists and information sources in the journalistic coverage of crises and emergencies in Spain. El profesional de 
la Información, 29(2),1-12. https://doi.org/10.3145/ epi.2020.mar.11

Mayo-Cubero, M. (2017). La especialización periodística como herramienta estratégica en la comunicación de catástrofes. Madrid, España: Universidad Complutense de Madrid. Recuperado de https://eprints.ucm.es/42138/1/T38637.pdf

Ministerio del Interior. (2020). Orden INT/228/2020. Boletín Oficial del Estado, 68, 1-2. Recuperado de https://www.boe.es/buscar/pdf/2020/BOE-A-20203696-consolidado.pdf

Ministerio de la Presidencia, Relaciones con las Cortes e lgualdad. (2019). Orden PCI/487/2019. Boletín Oficial del Estado, 103, 43437-43455. Recuperado de https://www.boe.es/eli/es/o/2019/04/26/pci487/ dof/spa/pdf

Montuori Fernandes, C., Ademir de Oliveira, L., y Borges Gomes, V. (2020). As notícias falsas e a reconfiguração do campo jornalístico era da pósverdade. Revista de la Asociación Española de Investigación de la Comunicación, 7(13), 231249. https://doi.org/10.24137/raeic.7.13.11

Moreno, A. (2020, 27 de abril). Elena Lázaro: Presidenta de la Asociación española de comunicación científica "Todos debemos actuar como cortafuegos de los bulos". Público. Recuperado de https://www.publico. es/sociedad/debemos-actuar-cortafuegos-bulos.html

Muñoz-Machado Cañas, J. (2020). Noticias falsas: Confianza y configuración de la opinión pública en los tiempos de internet. El Cronista del Estado Social y Democrático de Derecho, 86-87, 122138. Recuperado de http://www.elcronista.es/ElCronista-n\%C3\%BAmero-86-87-Coronavirus.pdf

Real Decreto 463/2020, de 14 de marzo, por el que se declara el estado de alarma para la gestión de la situación de crisis sanitaria ocasionada por el COVID-19. Boletín Oficial del Estado. Madrid, 14 de marzo de 2020, núm. 67, pp. 25390-25400.

Real Decreto 465/2020, de 17 de marzo, por el que se modifica el Real Decreto 463/2020, de 14 de marzo, por el que se declara el estado de alarma para la gestión de la situación de crisis sanitaria ocasionada por el COVID-19. Boletín Oficial del Estado. Madrid, 18 de marzo de 2020, núm. 73, pp. 2594425945.
Real Decreto 476/2020, de 27 de marzo, por el que se prorroga el estado de alarma declarado por el Real Decreto 463/2020, de 14 de marzo, por el que se declara el estado de alarma para la gestión de la situación de crisis sanitaria ocasionada por el COVID-19. Boletín Oficial del Estado. Madrid, 28 de marzo de 2020, núm. 86, pp. 27560-25561.

Real Decreto 487/2020, de 10 de abril, por el que se prorroga el estado de alarma declarado por el Real Decreto 463/2020, de 14 de marzo, por el que se declara el estado de alarma para la gestión de la situación de crisis sanitaria ocasionada por el COVID-19. Boletín Oficial del Estado. Madrid, 11 de abril de 2020, núm. 101, pp. 28858-28861.

Real Decreto 492/2020, de 24 de abril, por el que se prorroga el estado de alarma declarado por el Real Decreto 463/2020, de 14 de marzo, por el que se declara el estado de alarma para la gestión de la situación de crisis sanitaria ocasionada por el COVID-19. Boletín Oficial del Estado. Madrid, 25 de abril de 2020, núm. 115, pp. 30287-30294.

Onda cero (2020). Los bulos del coronavirus que circulan por redes sociales. Recuperado de https://www.ondacero.es/noticias/sociedad/buloscoronavirus-redes-sociales_202003265e7ca138462 6fc0001c3a243.html

Organización Mundial de la Salud. (2020). Recuperado de https://www.who.int/es

Ramonet, I. (2020, 25deabril). La pandemiayelsistemamundo. Le Monde Diplomatique. Recuperado de https://mondiplo.com/la-pandemia-y-el-sistema-mun do?fbclid=IwAR2ed9YLUIrni7XGgCXMtE5gYkU6LM 5rCQq0_XobLMqZCInS3MMPwOwpzXs

Real Academia Española (2020, 28 de abril). Posverdad. Diccionario de la lengua española. Recuperado de https://dle.rae.es/posverdad

Redacción Médica. (2020). Coronavirus: la OMS declaralapandemia anivelmundial porCovid-19. Recuperado de https://www.redaccionmedica.com/ secciones/sanidad-hoy/coronavirus-pandemia-brotede-covid-19-nivel-mundial-segun-oms-1895

Reglamento (UE) 2016/679 del Parlamento Europeo y del Consejo, de 27 de abril de 2016.). Diario Oficial de la Unión Europea. Luxemburgo, 4 de mayo de 2016, L- 2016-80807, pp. 1-88. 
Resolución del Parlamento Europeo, de 15 de junio de 2017, sobre las plataformas en línea y el mercado único digital (2016/2276(INI)). P8_TA(2017)0272. Diario Oficial de la Unión Europea. Luxemburgo, 18 de septiembre de 2018, C 331/135, pp. 1-11.

Revuelta, G. (2019). Comportamiento de la ciudadanía respecto a la información sobre salud: exposición, acceso y usos. Revista Española de Comunicación en Salud, 10(1), 9-20. https://doi. org/10.20318/recs.2019.4448

Rodríguez Pérez, C. (2019). No diga fake news, di desinformación: una revisión sobre el fenómeno de las noticias falsas y sus implicaciones. Comunicación, 40, 65-74. http://dx.doi.org/10.18566/comunica.n40. a05

Sánchez Ferriz, R., y Corredoira y Alfonso, L. (2017). La compleja configuración de un derecho-libertad poliédrico, el Derecho a la información: Referencias históricas. Revista de Derecho Político, 99, 11-48. Recuperado de http://revistas.uned.es/index.php/ derechopolitico/article/view/19305/16190 